Review

\title{
The prevalence and predictors of comorbid bipolar disorder and obsessive-compulsive disorder: A systematic review and meta-analysis
}

\author{
A. Amerio ${ }^{\mathrm{a}, \mathrm{b}, *}$, B. Stubbs ${ }^{\mathrm{c}}$, A. Odone ${ }^{\mathrm{d}, \mathrm{e}}, \mathrm{M}$. Tonna ${ }^{\mathrm{f}}$, C. Marchesi ${ }^{\mathrm{a}, \mathrm{f}}, \mathrm{S}$.N. Ghaemi ${ }^{\mathrm{b}, \mathrm{g}}$ \\ a Department of Neuroscience, Section of Psychiatry, University of Parma, Parma, Italy \\ ${ }^{\mathrm{b}}$ Mood Disorders Program, Tufts Medical Center, Boston, MA, USA \\ ' School of Health and Social Care, University of Greenwich, London, UK \\ d School of Medicine-Public Health Unit, University of Parma, Parma, Italy \\ e Department of Global Health and Social Medicine, Harvard Medical School, Boston, MA, USA \\ ${ }^{\mathrm{f}}$ Department of Mental Health, Local Health Service, Parma, Italy \\ ${ }^{g}$ Tufts University Medical School, Department of Psychiatry and Pharmacology, Boston, MA, USA
}

\section{A R T I C L E I N F O}

\section{Article history:}

Received 18 May 2015

Received in revised form

8 June 2015

Accepted 9 June 2015

Available online 26 July 2015

Keywords:

Bipolar disorder

Obsessive-compulsive disorder

prevalence

predictors

\begin{abstract}
A B S T R A C T
Background: Although some authors have recently investigated the co-occurrence of anxiety and bipolar disorders, the topic remains insufficiently studied. Defining the prevalence and predictors of BD-OCD comorbidity has important nosological, clinical and therapeutic implications.

Methods: A systematic review and meta-analysis was conducted on the prevalence and predictors of comorbid BD-OCD. Relevant papers published through March 30th, 2015 were identified searching the electronic databases MEDLINE, Embase, PsycINFO and the Cochrane Library.

Results: 46 articles met inclusion criteria. The pooled prevalence of OCD in BD was 17.0\% (95\% CI 12.7$22.4 \%$ ), which was comparable to the results reported by the pooled prevalence of BD in OCD $(18.35 \%$, $95 \%$ CI 13.2-24.8\%). With regard to OCD-BD predictors, a higher mean age predicted a lower prevalence of OCD in BD patients. Sub group meta-analyses reported higher OCD prevalence rates in BD children and adolescents (24.2\%, compared to $13.5 \%$ in adults), in BD-I patients (24.6\%, compared to $13.6 \%$ in mixed BD patients), and among population-based studies (22.2\%, compared to $13.2 \%$ in hospital-based studies).

Limitations: Most studies use retrospective assessment scales with low sensitivity in discriminating true ego-dystonic obsessions from depressive ruminations that may bias results towards an overestimation of obsessive symptom prevalence.

Conclusions: This first systematic review and meta-analysis of the prevalence and predictors of comorbid BD-OCD confirms that BD-OCD comorbidity is a common condition in psychiatry with children and adolescents and BD-I patients as the most affected subgroups.
\end{abstract}

(c) 2015 Elsevier B.V. All rights reserved.

\section{Contents}

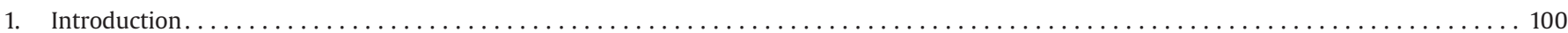

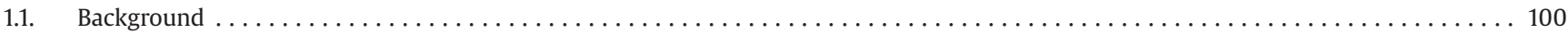

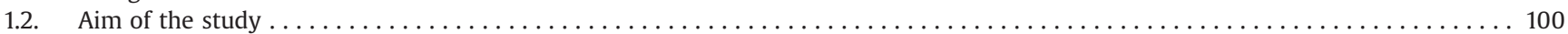

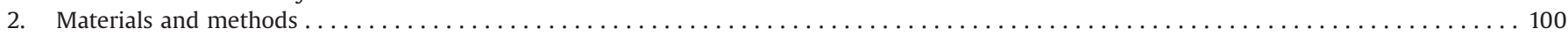

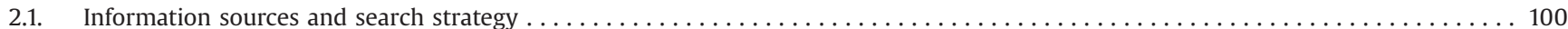

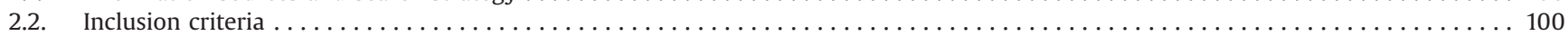

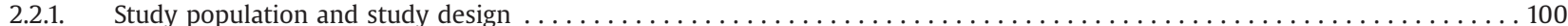

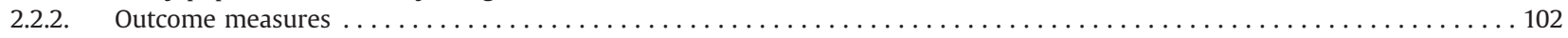

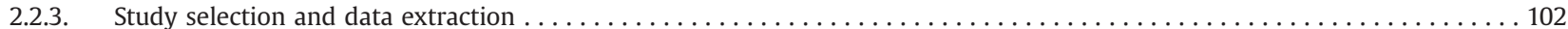

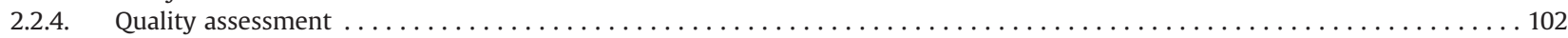

\footnotetext{
* Corresponding author at: Section of Psychiatry, Department of Neuroscience, University of Parma, c/o Ospedale Maggiore, Pad. 21-Braga, Viale A. Gramsci 14, 43126 Parma, Italy. Fax: + 390521347047.

E-mail addresses: andrea.amerio@studenti.unipr.it (A. Amerio), brendon.stubbs@kcl.ac.uk (B. Stubbs), anna.odone@mail.harvard.edu (A. Odone), mtonna@ausl.pr.it (M. Tonna), carlo.marchesi@unipr.it (C. Marchesi),nghaemi@tuftsmedicalcenter.org (S.N. Ghaemi).
} 


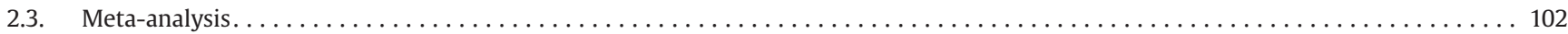

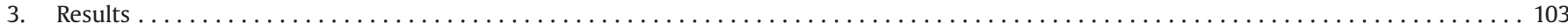

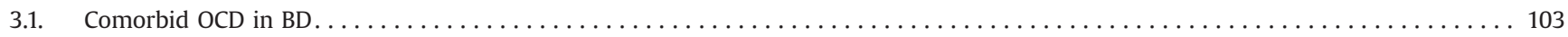

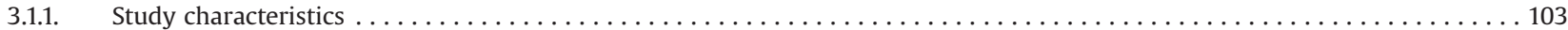

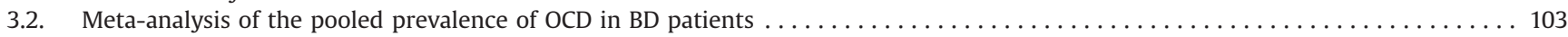

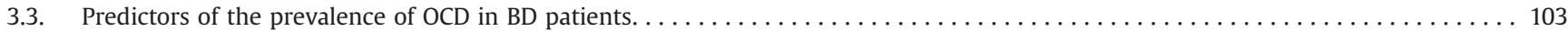

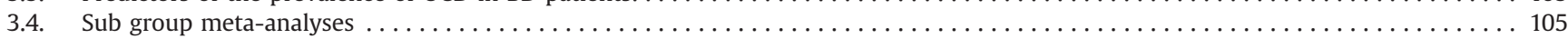

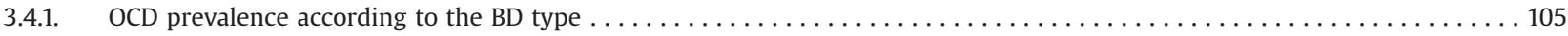

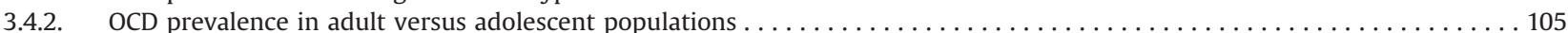

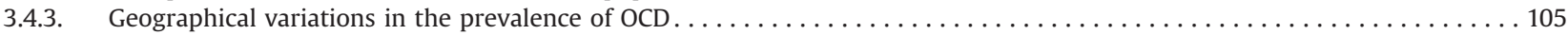

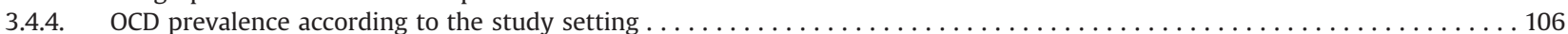

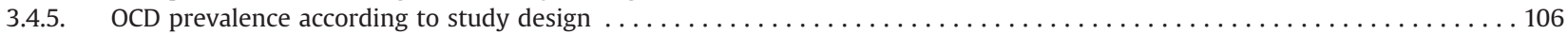

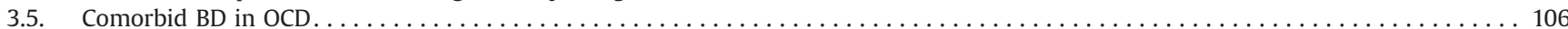

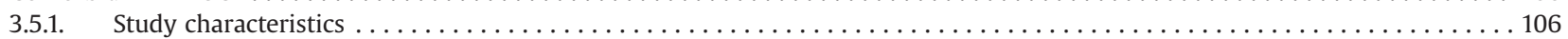

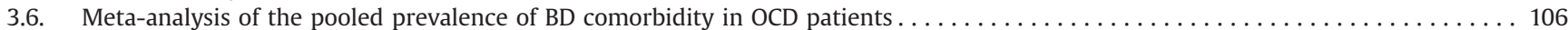

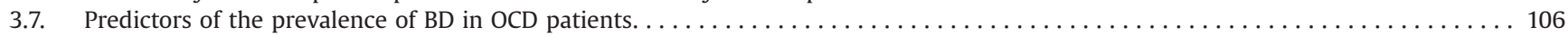

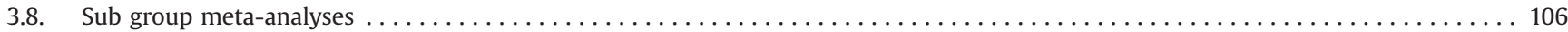

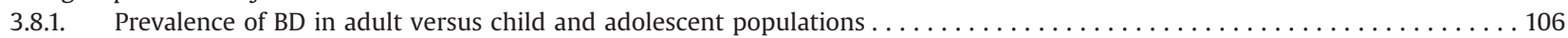

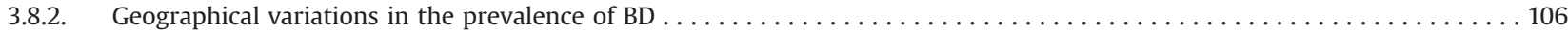

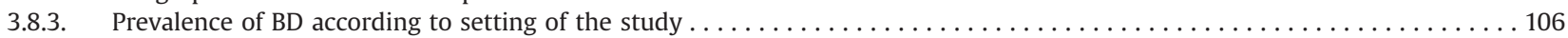

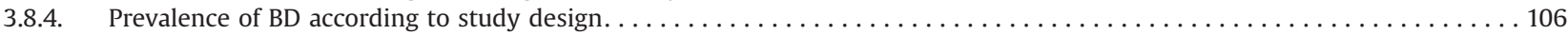

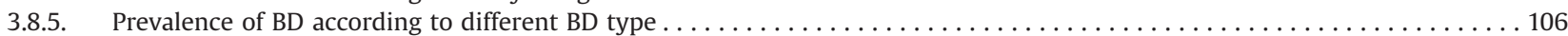

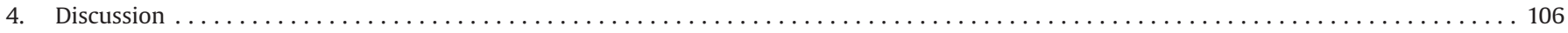

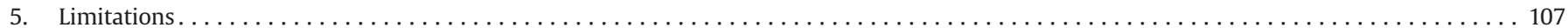

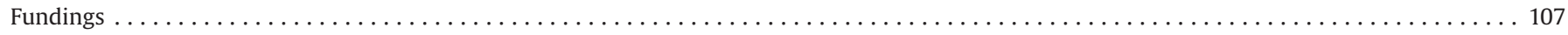

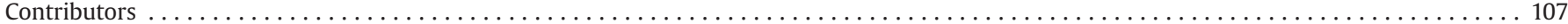

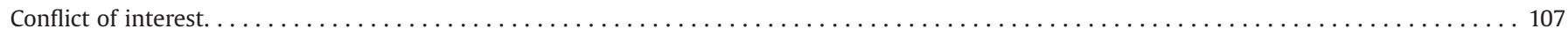

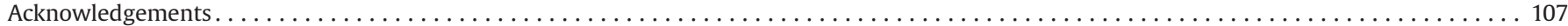

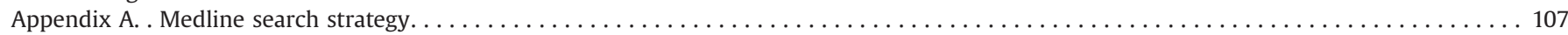

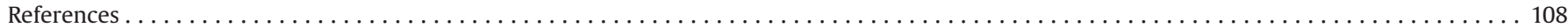

\section{Introduction}

\subsection{Background}

Apparent comorbidity between bipolar disorder (BD) and obsessive-compulsive disorder (OCD) is a common condition in psychiatry and it has important nosological and therapeutic implications (Tonna et al., 2015, Amerio et al., 2014c, 2014a, 2014b).

In our previous systematic review, we founded that $50-75 \%$ of OCD cases are limited to mood episodes in BD (Amerio et al., 2014a). OC symptoms in comorbid patients appeared more often-and sometimes exclusively-during depressive episodes, and comorbid BD and OCD cycled together, with OC symptoms often remitting during manic/ hypomanic episodes. In other words, especially among patients with a primary diagnosis of $\mathrm{BD}$, the majority of comorbid OCD cases appeared to be secondary to mood episodes (Amerio et al., 2014a).

However, although some authors have recently investigated the co-occurrence of anxiety and bipolar disorders, no meta-analysis of prevalence rates or subgroup analyses were performed (Vazquez et al., 2014).

Adopting a meta-analytic approach provides the advantage of pooling data from numerous studies in a logical manner to provide a more accurate effect size which is closer to the true prevalence than when individual studies are considered separately (Ioannidis, 2009). Moreover, from a clinical prospective, it could be important to know the different rates of BD-OCD comorbid prevalence in adults and children/adolescents, in different types of BD, study settings or designs, geographical variations.

The present paper is the first systematic review and metaanalysis of the prevalence and predictors of comorbid BD-OCD.

\subsection{Aim of the study}

We updated our previous systematic review and performed a meta-analysis of the evidence from the literature to define the prevalence and predictors of comorbid BD-OCD.

\section{Materials and methods}

We conducted this review according to the methods recommended by the Cochrane Collaboration (Higgins and Green, 2011) and to the Meta-analysis Of Observational Studies in Epidemiology (MOOSE) guidelines (Stroup et al., 2000) and documented the process and results in accordance with the Preferred Reporting Items for Systematic Reviews and Meta-Analyses (PRISMA) guidelines (Liberati et al., 2009).

\subsection{Information sources and search strategy}

Studies were identified searching the electronic databases MEDLINE, Embase, PsycINFO and the Cochrane Library. We combined the search strategy of free text terms and exploded MESH headings for the topics of bipolar disorder and obsessive-compulsive disorder combined as following: $(((((($ Bipolar disorder) OR BD) OR Bipolar) OR Manic depressive disorder) OR Manic depressive) OR Manic)) AND (((Obsessive-compulsive disorder) OR Obsessive-compulsive) OR OCD). The strategy was first developed in MEDLINE and then adapted for use in the other databases (Appendix A). Studies published in English through March 30th, 2015 were included. In addition, further studies were retrieved from reference listing of relevant articles and consultation with experts in the field.

\subsection{Inclusion criteria}

\subsubsection{Study population and study design}

We considered studies that included BD and OCD subjects if diagnostic criteria used were specified. Among BD study 


\begin{tabular}{|c|c|c|c|c|c|c|}
\hline References & Study design & Country & Study population & Sample size & Diagnosis assessment & Quality $^{a}$ \\
\hline \multicolumn{7}{|l|}{ Population-based studies } \\
\hline Adam et al. (2012) & Cross-sectional study & Germany & 4181 subjects (age range $=18-65)$ : OCD $(n=30)$ & 30 & $\begin{array}{l}\text { Broad concept of OCD; DIA-X/M-CIDI; } \\
\text { DSM-IV }\end{array}$ & $25 / 31$ \\
\hline Angst et al. (2004) ${ }^{b}$ & $\begin{array}{l}\text { Prospective cohort } \\
\text { study }\end{array}$ & Switzerland & 591 subjects recruited at age $19 / 20$ and assessed over 20 years: OCD $(n=30)$ & 30 & $\begin{array}{l}\text { Broad definition for BD and OCD; } \\
\text { DSM-IV }\end{array}$ & $26 / 31$ \\
\hline Chen and Dilsaver (1995) & Cross-sectional study & USA & $\begin{array}{l}\text { Pt. with BD, unipolar disorder or any Axis I disorder other than bipolar or unipolar disorder } \\
(n=6622 \text {, age }>18) \text { : } \mathrm{BD}(n=167)\end{array}$ & 167 & DIS; DSM-III & $25 / 31$ \\
\hline Faravelli et al. (2004) & Cross-sectional study & Italy & $\begin{array}{l}2500 \text { subjects randomly selected from the lists of } 15 \mathrm{GPs} \text { BD }(n=19 \text {, age }>14) \text {, OCD }(n=57 \text {, } \\
\text { age }>14)\end{array}$ & 76 & SCID; DSM-IV & $24 / 31$ \\
\hline Fineberg et al. (2013) ${ }^{b}$ & $\begin{array}{l}\text { Prospective cohort } \\
\text { study }\end{array}$ & Switzerland & 591 subjects recruited at age 19/20 and assessed over 30 years: OCD $(n=30)$ & 30 & $\begin{array}{l}\text { Broad definition for BD and OCD; } \\
\text { SPIKE; DSM-IV }\end{array}$ & $25 / 31$ \\
\hline Fireman et al. $(2001)^{c}$ & Cross-sectional study & USA & 1.728.480 subjects (age $>6$ ): adults with OCD $(n=1078)$ & 1078 & NS; DSM-IV & $24 / 31$ \\
\hline Fireman et al. $(2001)^{c}$ & Cross-sectional study & USA & 1.728 .480 subjects (age $>6)$ : children and adolescents with OCD $(n=198)$ & 198 & NS; DSM-IV & $24 / 31$ \\
\hline Merikangas et al. (2007) & Cross-sectional study & USA & 9282 subjects recruited (age $\geq 18$ ): adults with any BD $(n=408)$. & 408 & CIDI; SCID; DSM-IV & $25 / 31$ \\
\hline \multicolumn{7}{|c|}{ Hospital-based studies: adults } \\
\hline Boylan et al. (2004) & $\begin{array}{l}\text { Prospective cohort } \\
\text { study }\end{array}$ & Canada & $\mathrm{BD}(n=138$, age range $=16-65)$ & 138 & SCID; DSM-IV & $22 / 31$ \\
\hline Centorrino et al. (2006) & Case control study & USA & Adults $(n=62)$ with BD, OCD or BD-OCD & 62 & NS; DSM-IV & $20 / 31$ \\
\hline Cosoff and Hafner (1998) & Case control study & Australia & $\begin{array}{l}\text { Subjects with a psychotic disorder }(n=100, \text { mean age: } \text { men }=34.8 \pm 10.0 \text {, } \\
\text { women }=34.9 \pm 9.6): \operatorname{BD}(n=20)\end{array}$ & 20 & SCID-P; DSM-III-R & $20 / 31$ \\
\hline Craig et al. (2002) & Cross-sectional study & USA & 450 subjects: $\mathrm{BD}$ with psychosis $(n=138$, mean age range $=15-60)$ & 138 & SCID; DSM-III-R & $22 / 31$ \\
\hline Dilsaver et al. (2008) & Case control study & USA & $\begin{array}{l}187 \text { Latino pt. enroled consecutively from } 2001 \text { to 2003: BD-I }(n=69 \text {, mean } \\
\text { age }=34.9 \pm 11.8)\end{array}$ & 69 & SCID-CV; DSM-IV & $20 / 31$ \\
\hline Diniz et al. (2004) & Cross-sectional study & Brazil & OCD $(n=161$, mean age $=30 \pm 10))$ & 161 & SCID; DSM-IV & $21 / 31$ \\
\hline Edmonds et al. (1998) & Case control study & New Zealand & $\mathrm{BD}(n=55$, mean age $=41.6)$, first-degree relatives $(n=67$, mean age $=50.3)$ & 122 & DIGS; DSM-IV & $20 / 31$ \\
\hline Hantouche et al. (2003) & Case control study & France & OCD $(n=628$, mean age CYC-OCD $=35 \pm 12$, mean age NC-OCD $=36 \pm 14)$ & 628 & NS; DSM-IV & $24 / 31$ \\
\hline Henry et al. (2003) & Cross-sectional study & France & $\mathrm{BD}(n=318$, mean age $=53.3 \pm 15.1)$ & 318 & DIGS; DSM-IV & $23 / 31$ \\
\hline Kemp et al. (2014) & Clinical trial & USA & $\mathrm{BD}(\mathrm{BD}-\mathrm{I}$ or BD-II $)(n=264$, age $>18)$ & 264 & SCID; DSM-IV & $21 / 31$ \\
\hline Kim et al. (2014) & Cross-sectional study & South Korea & BD-I $(n=174$, age $>18)$ & 174 & SCID; DSM-IV & $22 / 31$ \\
\hline Koyuncu et al. (2010) & Case control study & Turkey & $\mathrm{BD}(n=214$, mean age: $\mathrm{BD}=34.8 \pm 10.3, \mathrm{OCD}-\mathrm{BD}=36.2 \pm 15.9)$ & 214 & SCID; DSM-IV & $20 / 31$ \\
\hline Kruger et al. (1995) & Cross-sectional study & Germany & Major affective disorder $(n=149$, mean age $=49 \pm 12): \mathrm{BD}(n=44)$ & 37 & DIS; DSM-III & $21 / 31$ \\
\hline Kruger et al. (2000) & Case control study & Germany & BD-I or BD-II $(n=143$, mean age $=44)$ & 143 & SCID; DSM-III-R & $22 / 31$ \\
\hline Magalhaes et al. (2010) & Case control study & Brazil & $\mathrm{BD}(n=259$, mean age $=41)$ & 259 & SCID; DSM-IV & $23 / 31$ \\
\hline Maina et al. (2007) & Case control study & Italy & OCD $(n=204$, mean age $=34.7 \pm 12.1)$ & 204 & SCID; DSM-IV & $21 / 31$ \\
\hline Marazziti et al. (2002) & Cross-sectional study & Italy & $\mathrm{OCD}(n=117$, mean age $=30 \pm 9.3)$ & 117 & SCID-P; DSM-IV & $21 / 31$ \\
\hline McElroy et al. (2001) & Case control study & USA & BD-I or BD-II $(n=288$, mean age $=42.8 \pm 11.3)$ & 288 & SCID-P; DSM-IV & $23 / 31$ \\
\hline Perugi et al. (1997) & Case control study & Italy & $\mathrm{OCD}(n=315$, mean age: $\mathrm{BD}-\mathrm{OCD}=32.8+12.2, \mathrm{OCD}=32.5 \pm 12.6)$ & 345 & NS; DSM-III-R & $22 / 31$ \\
\hline Perugi et al. (1998) & Case control study & Italy & OCD $(n=135$, mean age $=38.4 \pm 13.3)$ & 135 & NS; DSM-III-R & $21 / 31$ \\
\hline Perugi et al. (1999) & Case control study & Italy & 269pt. enroled consecutively from 1993 to 1995 : OCD ( $n=79$, mean age $=30.4 \pm 11.8$ ) & 79 & SCID-Up-R; DSM-III-R & $20 / 31$ \\
\hline Perugi et al. (2002) & Case control study & Italy & OCD-MDE $(n=68$, mean age $=34.2 \pm 12.5) ;$ BD-OCD $(n=38$, mean age $=35.9 \pm 12.2)$ & 68 & SCID; DSM-IV & $20 / 31$ \\
\hline Saunders et al. (2012) & Cross-sectional study & USA & BD, type I or Schizoaffective Disorder, bipolar type $(n=736$, mean age $=42 \pm 12)$ & 736 & DIGS; DSM-IV & $19 / 31$ \\
\hline Shashidhara et al. (2015) & Cross-sectional study & India & BD-I $(n=396$, age $>18)$ & 396 & SCID; DSM-IV & $23 / 31$ \\
\hline Simon et al. (2003) & Case control study & USA & 236 subjects: $\mathrm{BD}(n=122$, mean age $=40.8 \pm 12.2)$ & 122 & SCID; DSM-IV & $23 / 31$ \\
\hline Simon et al. (2004) & Cross-sectional study & USA & $\mathrm{BD}(n=475$, mean age $=41.7 \pm 12.8)$ & 475 & MINI; DSM-IV & $23 / 31$ \\
\hline Strakowski et al. (1992) & Cross-sectional study & USA & $\mathrm{BD}(n=41$, mean age $=40.4 \pm 11.7)$ & 41 & SCID; DSM-III-R & $22 / 31$ \\
\hline Strakowski et al. (1998) & Cross-sectional study & USA & BD, manic or mixed with psychosis ( $n=77$, mean age $=25 \pm 6$ ) & 77 & SCID-P; DSM-III-R & $22 / 31$ \\
\hline Timpano et al. (2012) & Case control study & USA & OCD $(n=605$, mean age $=39.2)$ & 605 & SCID-P; DSM-IV & $20 / 31$ \\
\hline Tukel et al. (2007) & Case control study & Turkey & OCD $(n=128$, mean age $=29.3 \pm 10.8)$ & 128 & SCID-CV; DSM-IV & $21 / 31$ \\
\hline Zutshi et al. (2006) & Case control study & India & $\mathrm{BD}$ in remission $(n=80$, mean age $=30.06 \pm 7.77)$ & 80 & SCID-CV; DSM-IV & $22 / 31$ \\
\hline
\end{tabular}

\section{Hospital-based studies: children, adolescents} Dilsaver et al. (2006) Case control study Joshi et al. (2010)
Latino adolescents $(n=313): \mathrm{BD}(n=115$, mean age $=14.6 \pm 1.5)$

$\mathrm{OCD}(n=125$, age range $=6-17), \mathrm{BD}(n=82$, age range $=6-17)$ 


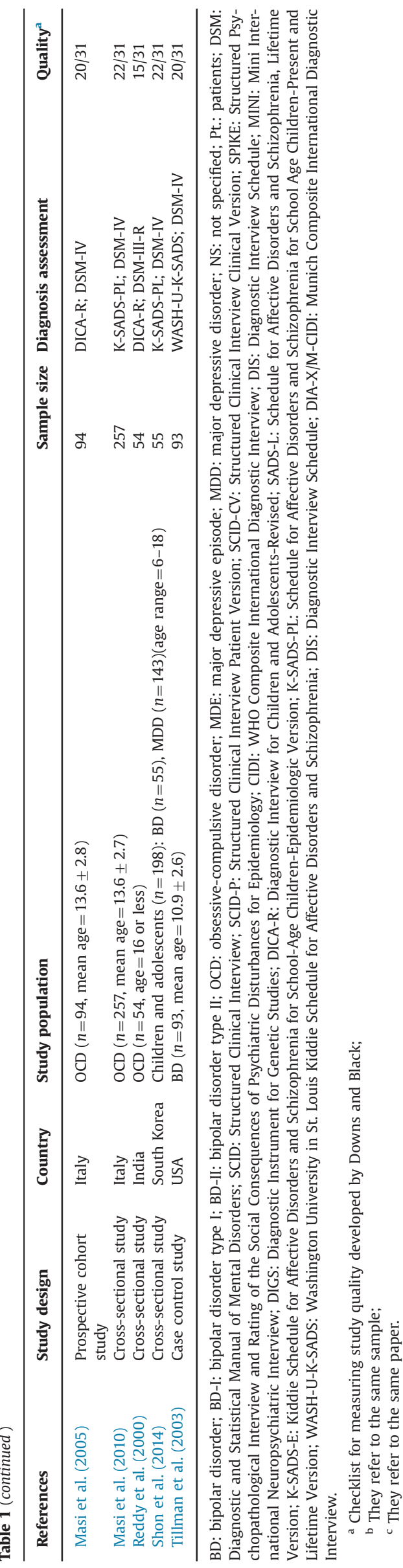

populations, studies that only focused on BD-I, BD-II or BD Non Otherwise Specified (Angst et al., 2004) were included. Studies that considered subjects with bipolar and obsessive-compulsive spectrums were also included if diagnostic criteria used were specified (Angst et al., 2004, Adam et al., 2012). Participants of both sexes older than 6 years of age were considered. Studies conducted on subjects with physical comorbidities such as lupus erythematous or Asperger's disorder were excluded as non-representative of the study population (Bachen et al., 2009, Mukaddes and Fateh, 2010).

Both population-based and hospital-based studies were included. Among hospital-based studies, inpatients, day-hospital and outpatient subjects were included while emergency care records were excluded as considered non-representative. All experimental and observational study designs were included apart from case reports. Narrative and systematic reviews, letters to the editor and book chapters were excluded.

\subsubsection{Outcome measures}

Primary outcomes were (i) lifetime prevalence of comorbid OCD in BD patients and (ii) lifetime prevalence of comorbid BD in OCD patients. Studies that reported only data about current prevalence were excluded (Dell'Osso et al., 2011). Secondary outcomes were potential predictors of comorbid BD-OCD.

\subsubsection{Study selection and data extraction}

Identified studies were independently reviewed for eligibility by two authors (AA, MT) in a two-step based process; a first screening was performed based on title and abstract while full texts were retrieved for the second screening. At both stages disagreements by reviewers were resolved by consensus. Data were extracted by one author (AA) and supervised by a second author (SNG) using an ad-hoc developed data extraction spreadsheet. The data extraction spreadsheet was piloted on 10 randomly selected papers and modified accordingly.

\subsubsection{Quality assessment}

The same authors who performed data extraction (AA, SNG) independently assessed the quality of selected studies using the checklist developed by Downs and Black both for randomised and non-randomised studies (Downs and Black, 1998). Disagreements by reviewers were resolved by consensus. Table 1 shows the quality assessment total score assigned to each study.

\subsection{Meta-analysis}

We pooled individual study data using DerSimonian-Laird proportion method (DerSimonian and Laird, 1986) with StatsDirect ${ }^{\mathbb{R}}$ and Comprehensive Meta-Analysis ${ }^{\mathbb{R}}$ software (version 3). Due to anticipated heterogeneity, a random effects meta-analysis was employed. If there were three or more studies with relevant data, we planned to calculate subgroup analyses of the prevalence of OCD according to geographical region, study setting (inpatient versus outpatient/ community), study sample (adolescents versus adults) and BD classification (BD-I versus BD-II and mixed). We also anticipated on conducting separate pooled prevalence of BD according to gender and also classification of BD itself. We assessed publication bias with the visual inspection of a funnel plot (Higgins and Green, 2011) and the Begg (Begg and Mazumdar, 1994) and Egger (Egger et al., 1997) tests. In addition, for the main prevalence analysis we conducted a trim and fill adjusted analysis to remove the most extreme small studies from the positive side of the funnel plot, recomputing the effect size at each iteration, until the funnel plot is symmetric about the (new) effect size (Duval and Tweedie, 2000). Finally, we conducted several meta-regression analyses (if $N \geq 3$ ) to investigate potential moderators (age, percentage males and study population) with Comprehensive Meta-Analysis ${ }^{\mathbb{R}}$ (version 3). 


\section{Results}

One thousand one hundred ninety-nine potential studies were identified from searching the selected databases and listing references of relevant articles. After removing duplicates, 756 articles were retrieved. Studies were screened and selected on the basis of pre-specified inclusion and exclusion criteria (Fig. 1). The search identified 46 articles that were included in the systematic review: 26 articles about comorbid OCD in BD, 19 articles about comorbid BD in OCD and one article that explore bidirectional BD-OCD comorbidity.

\subsection{Comorbid $O C D$ in $B D$}

\subsubsection{Study characteristics}

The characteristics of included studies are reported in Table 1. Thirteen of the twenty-seven studies were cross-sectional studies, twelve case-control studies, one prospective cohort study and one clinical trial. Three (11\%) studies were population-based while the majority $(N=24,89 \%)$ was hospital-based. Four studies considered specifically child and adolescent populations. In total 4983 BD patients were represented among the twenty-seven included studies. The mean age of BD patients was 31.0 (SD 12.2) and 40.3\% were males (12$76.8 \%)$. The majority of the studies were conducted in North America $(N=14,52 \%)$. In all the considered studies diagnosis of BD and OCD were based on the Diagnostic and Statistical Manual (DSM) criteria and were established using validated assessment scales. Three studies considered specifically BD-I patients.

\subsection{Meta-analysis of the pooled prevalence of $O C D$ in $B D$ patients}

Four thousand nine hundred eighty-three BD patients were included in the analysis and the pooled prevalence of OCD was $14.9 \%(95 \%$ $\mathrm{CI}=11.3-18.88, Q=324(\mathrm{df}=26)$ ) (Fig. 2a). The funnel plot for the main analysis appeared asymmetrical (Fig. 2b) and the Begg (Kendall's tau $=0.45, P=0.0009$ ) and Egger tests (Egger: bias $=4.17, P=0.001)$ indicated publication bias was present. Given this publication bias, OCD prevalence was recalculated with the trim and fil method and six studies were trimmed with a new prevalence of $17.0 \%$ (95\% CI, 12.7-22.4\%).

\subsection{Predictors of the prevalence of $O C D$ in $B D$ patients}

Considering data from 18 studies, a higher mean age predicted a lower prevalence of OCD in BD patients (co-efficient $=-0.0358$, $95 \% \mathrm{CI} 0.0669$ to $-0.0048, z=-2.26$ ). The percentage of males in the studies was not related to the prevalence of OCD (co efficient $=0.0097,95 \% \mathrm{CI}-0.0191$ to $0.0385, z=0.66$ ). There was a trend for studies conducted in adults to predict a lower prevalence of OCD (co efficient $=-0.8078,95 \% \mathrm{CI}-1.7325$ to $0.117, z=-1.71$ ).

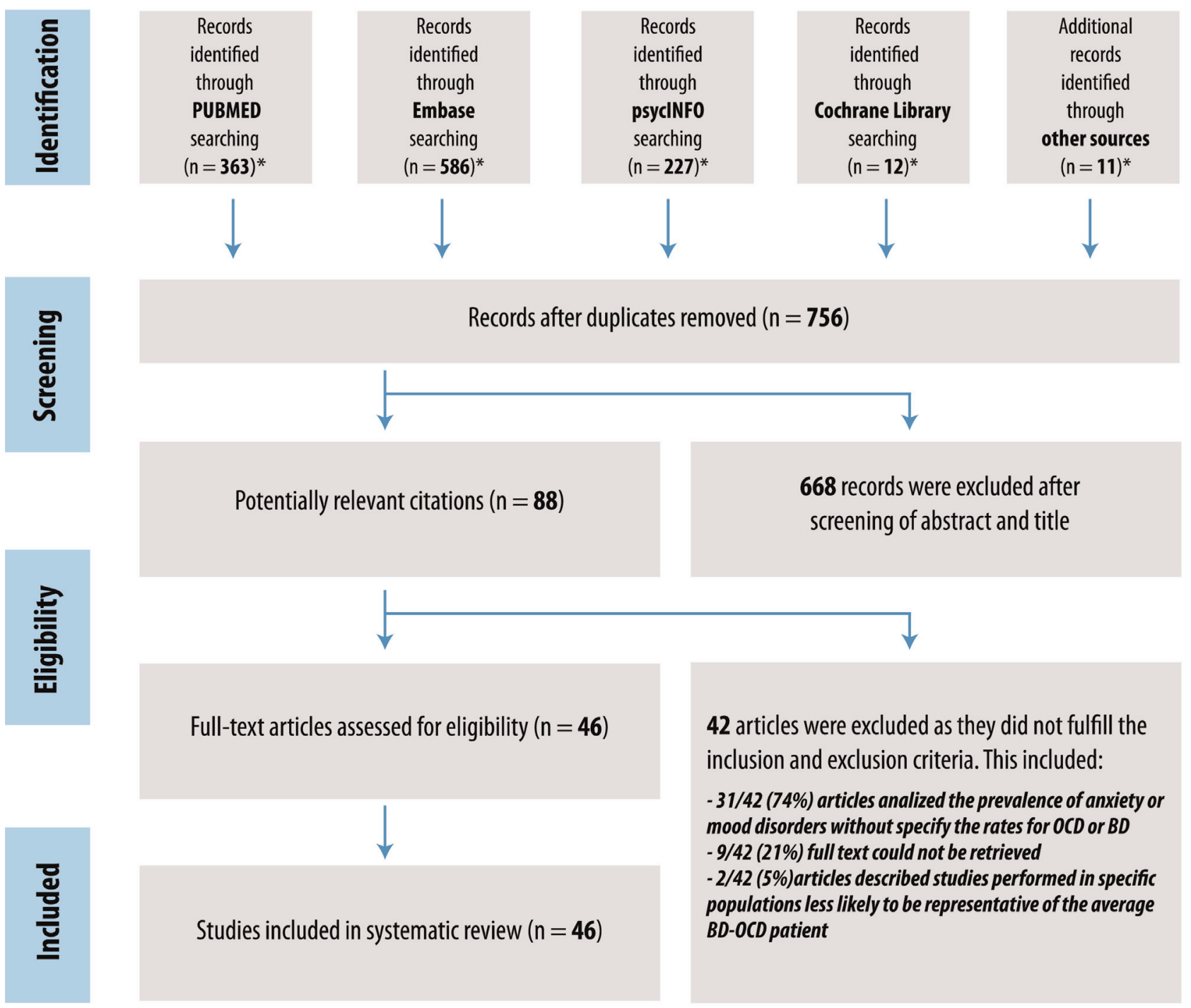

Fig. 1. Flow diagram of selected articles. 
a

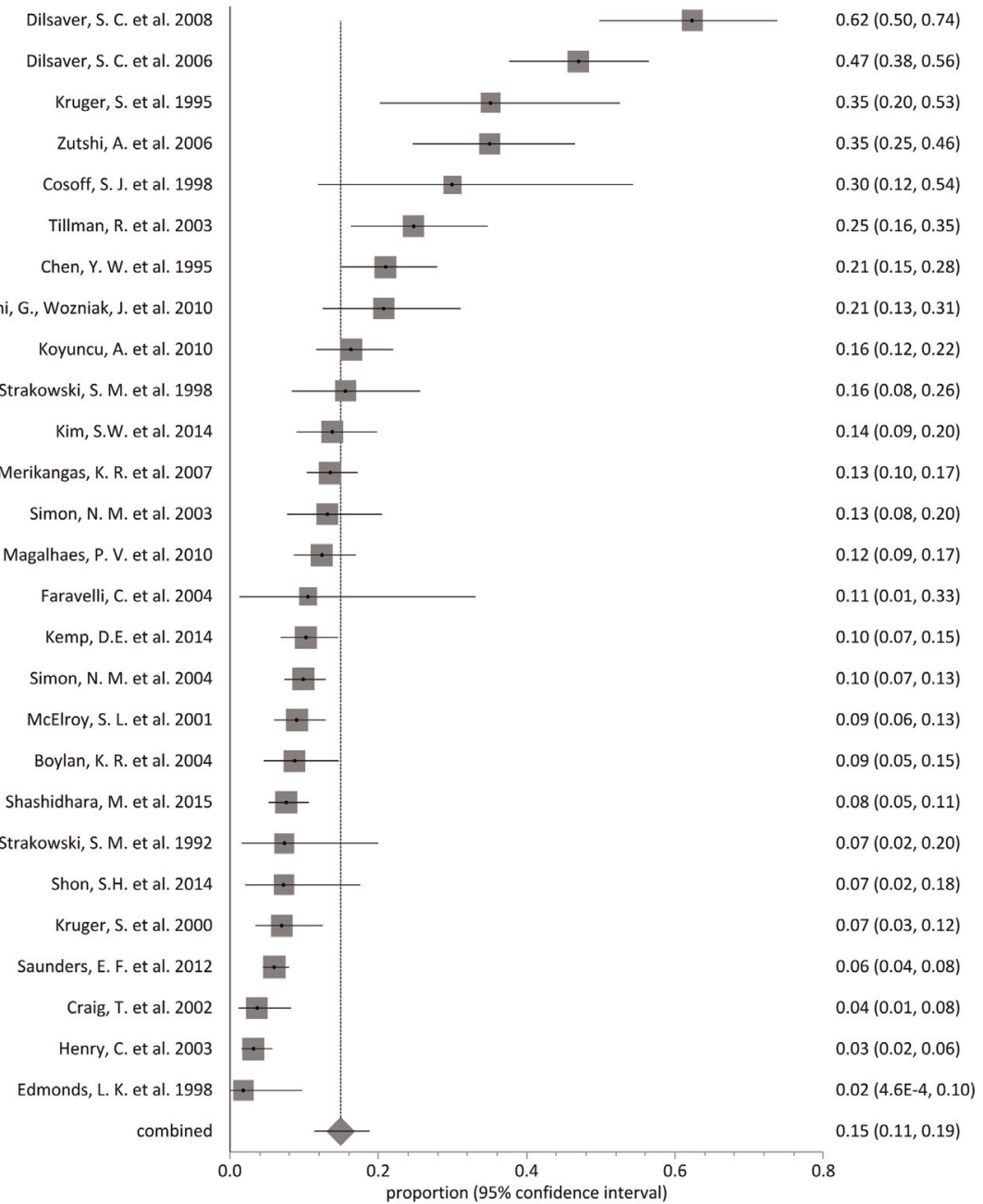

b

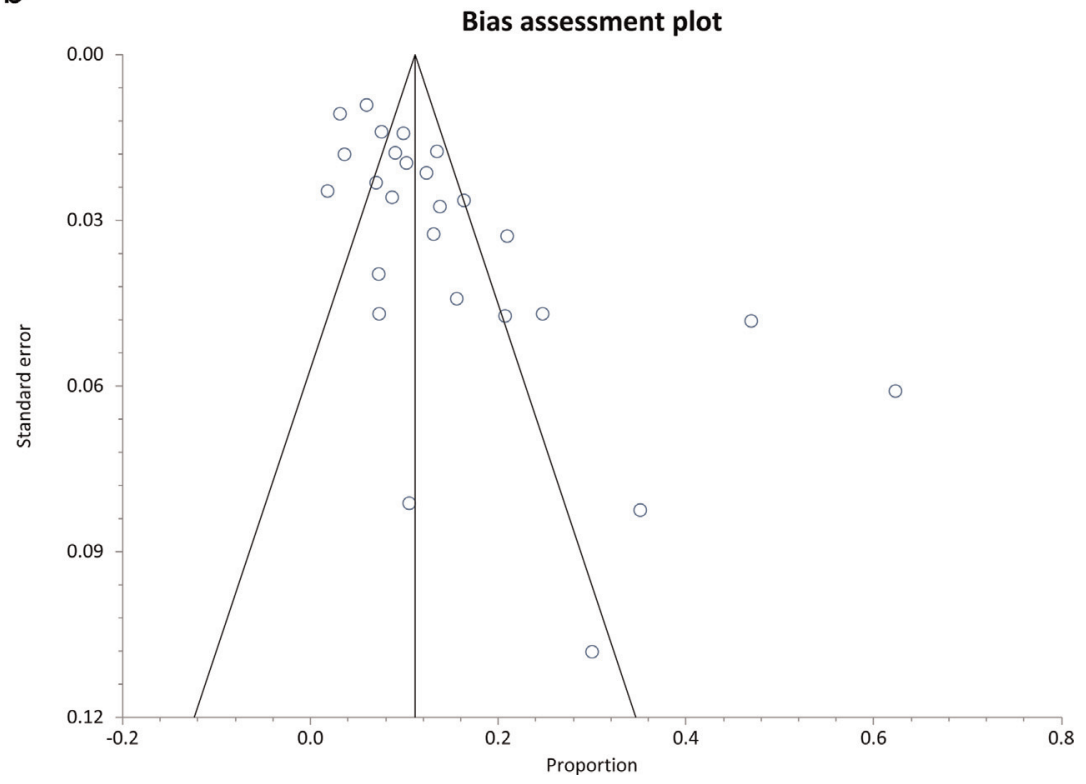

Fig. 2. (a) Pooled prevalence of $O C D$ in BD patients. (b) Funnel plot for the main analysis. 
a
Proportion meta-analysis plot [random effects]

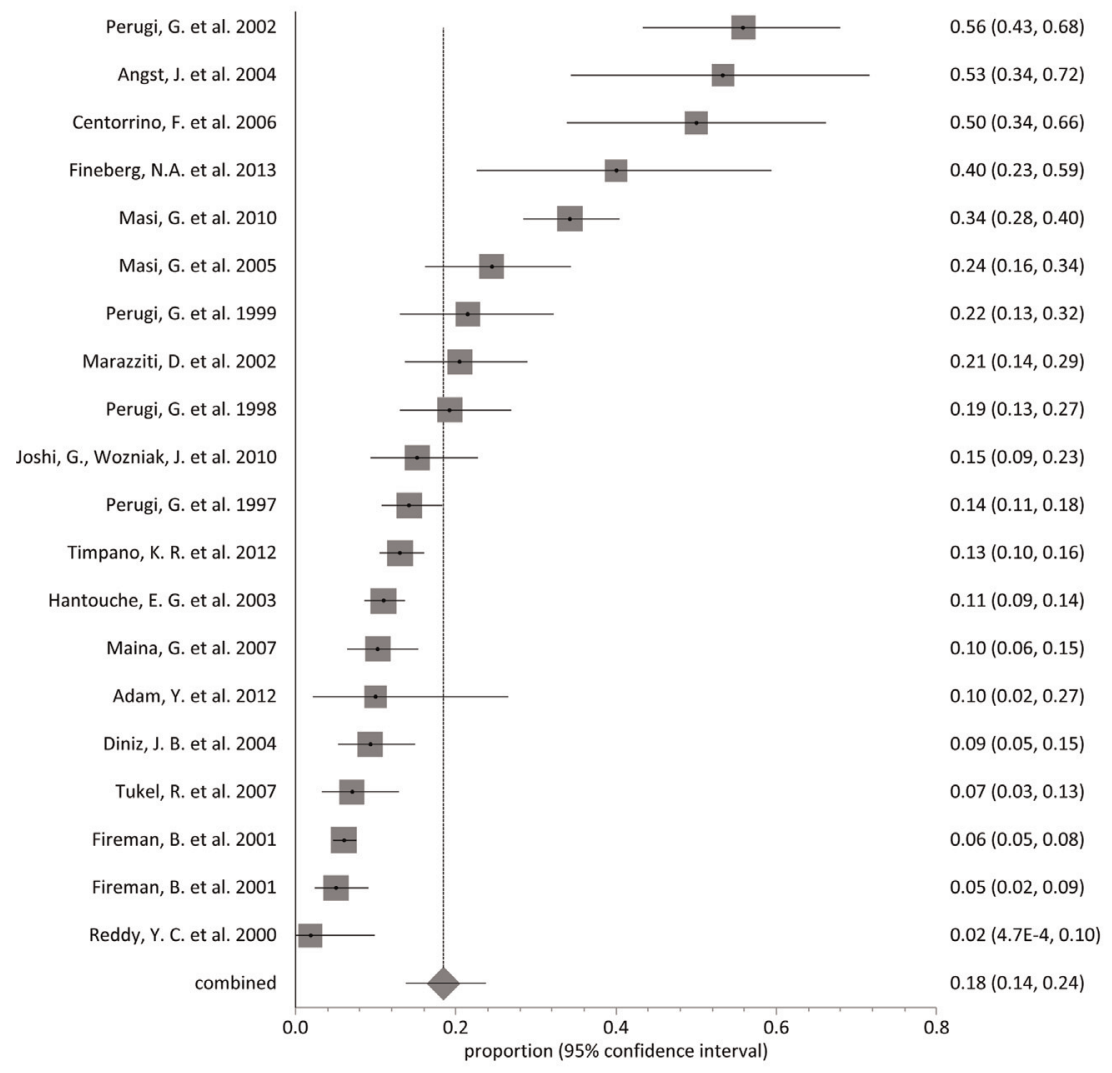

b

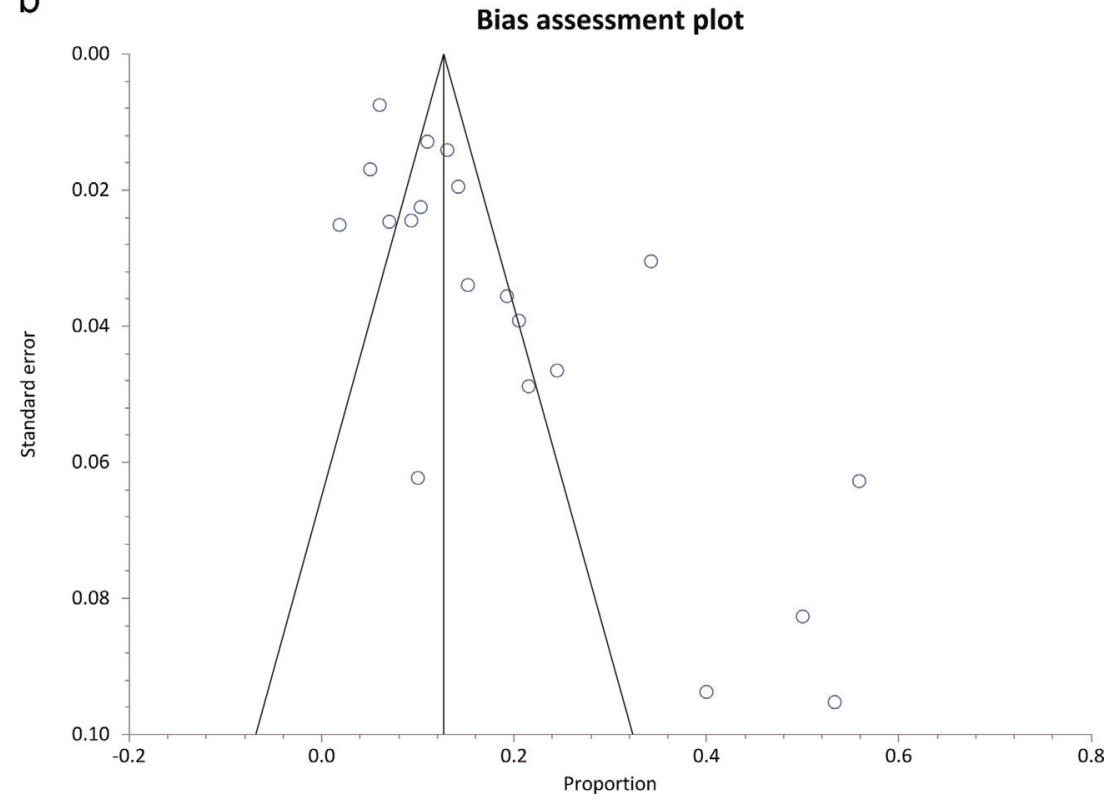

Fig. 3. (a) Pooled prevalence of BD in OCD patients. (b) Funnel plot for main analysis.

\subsection{Sub group meta-analyses}

\subsubsection{OCD prevalence according to the $B D$ type}

OCD prevalence among three studies conducted in BD-I patients was $24.62 \%$ (95\% $\mathrm{CI}=4.86-53.0 \%, n=639)$, while OCD prevalence among studies conducted in mixed BD patients (BD-I, BDII, BD NOS) was lower at $13.6 \%$ (95\% CI 10.2-16.8, $n=4264$, $z=-2.5)$.
3.4.2. OCD prevalence in adult versus adolescent populations

OCD prevalence among studies conducted in adults $(N=22)$ was $13.56 \%$ ( $95 \% \mathrm{CI}=10.4-16.25, n=4539)$. The pooled OCD prevalence of OCD among studies conducted in children and adolescents $(n=4)$ was significantly higher at $24.2 \%(95 \% \mathrm{CI}=10.36$ 41.60, $n=345, z=-9.5)$.

3.4.3. Geographical variations in the prevalence of $O C D$ The pooled OCD prevalence in BD patients among studies 
conducted in North America (16.4\%, 95\% CI=11.22-22.28, $N=16$, $n=3213)$ was higher compared to European $(11.7 \%, 95 \% \mathrm{CI}=2.4-$ 26.6, $N=3, n=498, z=4.0)$ and Asian studies $(10.6 \%, 95 \% \mathrm{CI}=6.8-$ $14.5, N=4, n=705, z=2.6$ ).

\subsubsection{OCD prevalence according to the study setting}

Three population-based studies reported a pooled OCD prevalence of $22.2 \%$ (95\% CI $6.1-44.8 \%, n=467$ ) in BD patients. The prevalence of OCD in BD patients among hospital-based studies was lower at $13.2 \%$ (95\% CI 9.9-16.8\%, $n=4436, z=6.7)$.

\subsubsection{OCD prevalence according to study design}

Eleven case control studies reported a pooled OCD prevalence of $13.6 \%$ (95\% CI $10.1-17.5 \%, n=2037$ ) in BD patients. The prevalence of OCD in BD patients among cross sectional studies was $12.0 \%$ (95\% CI 7.4-17.6\%, $n=2389, z=1.9$ ).

\subsection{Comorbid $B D$ in $O C D$}

\subsubsection{Study characteristics}

The characteristics of included studies are reported in Table 1. Ten of the twenty studies were case-control studies, seven crosssectional studies and three prospective cohort studies. Five studies (25\%) were population-based while the majority $(N=15,75 \%)$ was hospital-based. Five studies considered specifically child and adolescent populations. In total $4406 \mathrm{BD}$ patients were represented among the twenty included studies. The mean age of BD patients was 25.3 (SD 10.18) and $47.5 \%$ were males (36.6-69\%). The majority of the studies were conducted in Europe $(N=12,60 \%)$. In all the considered studies diagnosis of BD and OCD were based on the Diagnostic and Statistical Manual (DSM) criteria and were established using validated assessment scales.

\subsection{Meta-analysis of the pooled prevalence of $B D$ comorbidity in OCD patients}

Four thousand four hundred six OCD patients were included in the analysis and the pooled prevalence of BD was $18.47 \%$ (95\% CI 13.7-23.7, $Q=380$ ) (Fig. 3a). The funnel plot for the main analysis appeared somewhat asymmetrical (Fig. $3 \mathrm{~b})$ and the Begg (0.46, $P=0.0038$ ) and Egger tests (Egger: bias $=4.4, P=0.003$ ) indicated publication bias was present. Given this publication bias, the $\mathrm{BD}$ prevalence was recalculated with the trim and fil method with a new prevalence of $18.35 \%$ (95\% CI $13.2-24.8 \%$ ).

\subsection{Predictors of the prevalence of $B D$ in $O C D$ patients}

Meta regression analysis demonstrated that mean age (co-efficient $-0.0235,95 \% \mathrm{CI}-0.0599$ to $0.0129, z=-1.27$ ) and mean percentage of males (co efficient $0.006,95 \% \mathrm{CI}-0.0308$ to 0.0429 , $z=0.32$ ) did not predict the prevalence of BD in the OCD samples. In addition, no relationship was observed in the meta regression analysis on the study setting or sample population (adults or adolescent).

\subsection{Sub group meta-analyses}

\subsubsection{Prevalence of $B D$ in adult versus child and adolescent populations}

BD prevalence in OCD patients (age $>18$ ) among 15 studies was $19.6 \%$ (95\% CI 14.4-25.3, $n=3678$ ). Five studies considered specifically children and adolescents with OCD and BD prevalence was 14.6\% (95\% CI 4.5-29.1, $n=728$ ).

3.8.2. Geographical variations in the prevalence of $B D$

The pooled prevalence of $\mathrm{BD}$ among $\mathrm{OCD}$ patients among studies $(N=5)$ conducted in North America was $14.1 \%$ (95\% CI 7.5$22.3 \%, n=2046)$. The pooled prevalence of $\mathrm{BD}$ in studies conducted in Europe $(N=12)$ was $24.4 \%$ (95\% CI 17.3-32.2, $n=2017, z=-8.8$ ).

\subsubsection{Prevalence of $B D$ according to setting of the study}

Fifteen hospital-based studies investigated BD prevalence among OCD patients with a pooled prevalence of $18.59 \%$ (95\% CI 13.6-24.1) which was comparable to the results reported by the five population-based studies (18.56\%, 95\% CI 7.8-32.6\%).

\subsubsection{Prevalence of $B D$ according to study design}

The pooled BD prevalence in OCD patients was $20.6 \%(95 \% \mathrm{CI}$ $14.5-27.5 \%, n=2614)$ in case-control studies $(N=11), 8.39 \%(95 \% \mathrm{CI}$ 4.7-12.9\%, $n=1638, z=8.9)$ in cross-sectional studies $(N=6)$, and $37.9 \%(95 \%$ CI $21.3-56.2 \%, n=154)$ in prospective cohort studies $(N=3)$.

\subsubsection{Prevalence of $B D$ according to different $B D$ type}

There were insufficient data to conduct sub group analyses according to BD classification.

\section{Discussion}

Apparent comorbidity between bipolar disorder (BD) and obsessive-compulsive disorder (OCD) is a common condition in psychiatry. In a classic 1860 text French psychiatrist BénédictAugustin Morel described patients with comorbidity of symptoms typical of what are now considered BD and OCD (Morel, 1860). Although recent studies have recently investigated the prevalence of co-occurrence of anxiety and bipolar disorders (Vazquez et al. 2014), the topic remains insufficiently studied. However, given the available scientific evidence, some observations can be made.

The pooled prevalence of OCD in BD was $17.0 \%$, which was comparable to the results reported by the pooled prevalence of $\mathrm{BD}$ in OCD (18.35\%). With regard to OCD-BD predictors, a higher mean age predicted a lower prevalence of OCD in BD patients. Sub group meta-analyses reported higher OCD prevalence rates in BD children and adolescents (24.2\%, compared to $13.5 \%$ in adults), and especially in BD-I patients (24.6\%, compared to $13.6 \%$ in mixed BD patients). Higher OCD prevalence rates in BD among populationbased studies (22.2\%, compared to $13.2 \%$ among hospital-based studies) could be explain by low sensitivity assessment scales used to evaluate large sample of people.

Comparing studies conducted in North America and in Europe, the pooled prevalence of OCD among BD patients was higher in North America (16.4\% vs. $11.7 \%$ ), while the pooled prevalence of BD among OCD patients was higher in Europe (24.4\% vs. $14.1 \%$ ). Geographical variations between BD-OCD comorbidity prevalence rates could reflect different thresholds for BD diagnosis (i.e. categorical vs. dimensional approach) and a different accuracy in diagnosing OCD (i.e. discrimination between true ego-dystonic obsessions and depressive ruminations).

Considering the important nosological, clinical and therapeutic implications, the entire question of BD-OCD comorbidity deserves attention, which we have provided separately (Amerio et al., 2014a, 2014c, 2014b, Tonna et al., 2015).

From a nosological perspective, considering course of illness as a key diagnostic validator, especially among patients with a primary diagnosis of $\mathrm{BD}$, the majority of comorbid OCD cases appeared to be secondary to mood episodes (Amerio et al., 2014a). OC symptoms in comorbid patients appeared more often-and sometimes exclusively-during depressive episodes, and comorbid $\mathrm{BD}$ and OCD cycled together, with OC symptoms often remitting during manic/hypomanic episodes (Amerio et al., 2014a). These results confirm the hypothesis of Mayer-Gross and colleagues 
reported in a standard 1969 psychiatry textbook: "These people (BD-OCD patients) who, in time of health, show no noteworthy obsessional traits, but who have phases in which compulsive symptoms appear out of the blue and rapidly mount up to complete incapacitation.... Nevertheless these illnesses remit and relapse in very much the same way as cyclothymic illnesses, may show just as much regularity of timing, and are probably to be included, from the aetiological point of view, in the manic-depressive disorders" (MayerGross et al., 1969). On the contrary, especially among patients with a primary diagnosis of $O C D$, there is a substantial minority of comorbid BD-OCD that may represent "true" OCD independent of BD with OC symptoms that improve or worsen during mood episodes without being related to these.

With regard to the clinical meaning, OC symptoms (i) may be expression of a vulnerability to the development of BD preceding their clinical onset for many years; (ii) they may have a pathoplastic influence, especially in "soft" bipolar spectrum disorders (cyclothimia); and (iii) they might confer, at a mild level of severity, order and stability to daily life activity, thus compensating possible functioning decline in BD (Tonna et al., 2015).

Results from our meta-analysis would support the first hypothesis with higher comorbidity rates in youths compared to adults. As confirmed by recent studies, OC symptoms in childhood and adolescence would increase the risk of a later BD diagnosis preceding the BD onset (Cederlöf et al., 2014, D'Ambrosio et al., 2010). We speculate that OC symptoms initially would coexist with BD symptoms even cycling together and they gradually would tend to decrease in the adulthood.

From a therapeutic perspective, mood stabilisation should be the primary goal in treating BD-OCD patients. Benefit with neuroleptics was also seen, although a few reports also exist of exacerbation of OC symptoms with neuroleptic agents. Addition of SRI agents and other antidepressants seemed to be less effective and more harmful in BD-OCD than in non-comorbid patients. Nonetheless, in a minority of BD patients with refractory $O C D$, addition of low doses of antidepressants might also be considered while strictly monitoring emerging symptoms of mania and hypomania (Amerio et al., 2014c).

Further original studies are needed to clarify BD-OCD prevalence rates, diagnostic validity, clinical meaning and treatment approach. In particular, assessment scales with high sensitivity in discriminating true ego-dystonic obsessions from depressive ruminations are essential to estimate the real prevalence of obsessive symptoms in these patients.

\section{Limitations}

The main limitation of this systematic review is linked to the study design and analysis strategy of the included studies, as documented in the quality assessment scale used. Most studies are observational and based on retrospective assessments. The use of retrospective assessment scales with low sensitivity in discriminating true ego-dystonic obsessions from depressive ruminations may have biased results towards an overestimation of obsessive symptom prevalence. Some of them do not include a control group. Small sample size and enrolment of subjects mainly from BD-OCD outpatient units may limit generalisability of these results. Potential confounding factors in these studies include demographic and historical illness variables, which often were not appropriately analysed through multivariate modelling.

The strength of the selected studies is that the diagnosis of $\mathrm{BD}$ and OCD were consistently based on the DSM criteria and were established by trained investigators using validated assessment scales mainly with interrater reliability. The main strength of this review is its being systematic and its including the entire scientific evidence published so far on the main medical databases.

\section{Fundings}

This research received no specific grant from any funding agency in the public, commercial or not-for-profit sectors.

\section{Contributors}

Authors AA, AO, MT, CM and SNG designed the study and wrote the protocol. Studies were identified and independently reviewed for eligibility by two authors (AA, MT) in a two-step based process. Data were extracted by one author (AA) and supervised by a second author (SNG) using an ad-hoc developed data extraction spreadsheet. The same authors who performed data extraction (AA, SNG) independently assessed the quality of selected studies using the checklist developed by Downs and Black both for randomized and non-randomized studies. Author BS performed the meta-analysis and meta-regression of data. Authors AA, AO and BS wrote the first draught of the manuscript. Our manuscript has been approved by all authors.

\section{Conflict of interest}

Dr. Amerio, Dr. Stubbs, Dr. Odone, Dr. Tonna and Dr. Marchesi report no conflicts of interest.

Dr. Ghaemi has provided research consulting to Sunovion and Pfizer, and has obtained a research grant from Takeda Pharmaceuticals. Neither he nor his family hold equity positions in pharmaceutical corporations.

\section{Acknowledgements}

The authors thank Leonardo Amerio Odone for his help and support.

\section{Appendix A. Medline search strategy}

\begin{tabular}{ll}
\hline Set & Medline \\
\hline 1 & Bipolar disorder \\
2 & BD \\
3 & Bipolar \\
4 & Manic depressive disorder \\
5 & Manic depressive \\
6 & Manic \\
7 & Bipolar disorder \\
8 & Sets $1-7$ were combined with "OR"
\end{tabular}


11 OCD

12 Obsessive-Compulsive Disorder

13 Sets 9-12 were combined with "OR"

14 Sets 8 and 13 were combined with "AND"

15 Set 14 was limited to March 2015, Humans, English language, Child: 6-12 years, Adolescent: 13-18 years, Adult: 19+ years

Words written in italic were used as MeSH headings, the others were used as free text.

\section{References}

Adam, Y., Meinlschmidt, G., Gloster, A.T., Lieb, R., 2012. Obsessive-compulsive disorder in the community: 12-month prevalence, comorbidity and impairment. Soc. Psychiatry Psychiatr. Epidemiol. 47, 339-349.

Amerio, A., Odone, A., Liapis, C.C., Ghaemi, S.N., 2014a. Diagnostic validity of comorbid bipolar disorder and obsessive-compulsive disorder: a systematic review. Acta Psychiatr. Scand. 129, 343-358.

Amerio, A., Odone, A., Marchesi, C., Ghaemi, S.N., 2014b. Do antidepressant-induced manic episodes in obsessive-compulsive disorder patients represent the clinical expression of an underlying bipolarity. Aust. N. Z. J. Psychiatry 48, 957.

Amerio, A., Odone, A., Marchesi, C., Ghaemi, S.N., 2014c. Treatment of comorbid bipolar disorder and obsessive-compulsive disorder: a systematic review. J. Affect. Disord. 166, 258-263.

Angst, J., Gamma, A., Endrass, J., Goodwin, R., Ajdacic, V., Eich, D., Rossler, W., 2004. Obsessive-compulsive severity spectrum in the community: prevalence, comorbidity, and course. Eur. Arch. Psychiatry Clin. Neurosci. 254, 156-164.

Bachen, E.A., Chesney, M.A., Criswell, L.A., 2009. Prevalence of mood and anxiety disorders in women with systemic lupus erythematosus. Arthritis Rheum. 61, $822-829$.

Begg, C.B., Mazumdar, M., 1994. Operating characteristics of a rank correlation test for publication bias. Biometrics 50, 1088-1101.

Boylan, K.R., Bieling, P.J., Marriott, M., Begin, H., Young, L.T., Macqueen, G.M., 2004. Impact of comorbid anxiety disorders on outcome in a cohort of patients with bipolar disorder. J. Clin. Psychiatry 65, 1106-1113.

Cederlöf, M., Lichtenstein, P., Larsson, H., Boman, M., Rück, C., Landén, M., MataixCols, D. 2014. Obsessive-compulsive disorder, psychosis, and bipolarity: a longitudinal cohort and multigenerational family study. Schizophr. Bull. [Epub ahead of print].

Centorrino, F., Hennen, J., Mallya, G., Egli, S., Clark, T., Baldessarini, R.J., 2006. Clinical outcome in patients with bipolar I disorder, obsessive compulsive disorder or both. Hum. Psychopharmacol. 21, 189-193.

Chen, Y.W., Dilsaver, S.C., 1995. Comorbidity for obsessive-compulsive disorder in bipolar and unipolar disorders. Psychiatry Res. 59, 57-64.

Cosoff, S.J., Hafner, R.J., 1998. The prevalence of comorbid anxiety in schizophrenia, schizoaffective disorder and bipolar disorder. Aust. N. Z. J. Psychiatry 32, 67-72.

Craig, T., Hwang, M.Y., Bromet, E.J., 2002. Obsessive-compulsive and panic symptoms in patients with first-admission psychosis. Am. J. Psychiatry 159, 592-598.

D’ambrosio, V., Albert, U., Bogetto, F., Maina, G., 2010. Obsessive-compulsive disorder and cyclothymic temperament: an exploration of clinical features. J. Affect. Disord. 127, 295-299.

Dell'osso, B., Buoli, M., Bortolussi, S., Camuri, G., Vecchi, V., Altamura, A.C., 2011. Patterns of Axis I comorbidity in relation to age in patients with Bipolar Disorder: a cross-sectional analysis. J. Affect. Disord. 130, 318-322.

Dersimonian, R., Laird, N., 1986. Meta-analysis in clinical trials. Control Clin. Trials 7 , $177-188$.

Dilsaver, S.C., Akiskal, H.S., Akiskal, K.K., Benazzi, F., 2006. Dose-response relationship between number of comorbid anxiety disorders in adolescent bipolar/unipolar disorders, and psychosis, suicidality, substance abuse and familiality. J. Affect. Disord. 96, 249-258.

Dilsaver, S.C., Benazzi, F., Akiskal, K.K., Akiskal, H.S., 2008. Differential patterns of lifetime multiple anxiety disorder comorbidity between Latino adults with bipolar I and major depressive disorders. Bull. Menn. Clin. 72, 130-148.

Diniz, J.B., Rosario-Campos, M.C., Shavitt, R.G., Curi, M., Hounie, A.G., Brotto, S.A., Miguel, E.C., 2004. Impact of age at onset and duration of illness on the expression of comorbidities in obsessive-compulsive disorder. J. Clin. Psychiatry 65, 22-27.

Downs, S.H., Black, N., 1998. The feasibility of creating a checklist for the assessment of the methodological quality both of randomised and non-randomised studies of health care interventions. J. Epidemiol. Commun. Health 52, 377-384.

Duval, S., Tweedie, R., 2000. Trim and fill: a simple funnel-plot-based method of testing and adjusting for publication bias in meta-analysis. Biometrics 56, 455-463.

Edmonds, L.K., Mosley, B.J., Admiraal, A.J., Olds, R.J., Romans, S.E., Silverstone, T., Walsh, A.E., 1998. Familial bipolar disorder: preliminary results from the Otago Familial Bipolar Genetic Study. Aust. N. Z. J. Psychiatry 32, 823-829.

Egger, M., Davey Smith, G., Schneider, M., Minder, C., 1997. Bias in meta-analysis detected by a simple, graphical test. Br. Med. J. 315, 629-634.

Faravelli, C., Abrardi, L., Bartolozzi, D., Cecchi, C., Cosci, F., D’adamo, D., Lo Iacono, B., Ravaldi, C., Scarpato, M.A., Truglia, E., Rosi, S., 2004. The Sesto Fiorentino study: background, methods and preliminary results. Lifetime prevalence of psychiatric disorders in an Italian community sample using clinical interviewers. Psychother. Psychosom. 73, 216-225.

Fineberg, N.A., Hengartner, M.P., Bergbaum, C., Gale, T., Rossler, W., Angst, J., 2013. Lifetime comorbidity of obsessive-compulsive disorder and sub-threshold obsessive-compulsive symptomatology in the community: impact, prevalence, socio-demographic and clinical characteristics. Int. J. Psychiatry Clin. Pract. 17, 188-196.

Fireman, B., Koran, L.M., Leventhal, J.L., Jacobson, A., 2001. The prevalence of clinically recognized obsessive-compulsive disorder in a large health maintenance organization. Am. J. Psychiatry 158, 1904-1910.

Hantouche, E.G., Angst, J., Demonfaucon, C., Perugi, G., Lancrenon, S., Akiskal, H.S., 2003. Cyclothymic OCD: a distinct form? J. Affect. Disord. 75, 1-10.

Henry, C., van den Bulke, D., Bellivier, F., Etain, B., Rouillon, F., Leboyer, M., 2003. Anxiety disorders in 318 bipolar patients: prevalence and impact on illness severity and response to mood stabilizer. J. Clin. Psychiatry 64, 331-335.

Higgins, J., Green, S. 2011. Cochrane handbook for systematic reviews of interventions, version 5.1.0., The Cochrane Collaboration.

Ioannidis, J.P., 2009. Integration of evidence from multiple meta-analyses: a primer on umbrella reviews, treatment networks and multiple treatments meta-analyses. CMAJ 181, 488-493.

Joshi, G., Wozniak, J., Petty, C., Vivas, F., Yorks, D., Biederman, J., Geller, D., 2010. Clinical characteristics of comorbid obsessive-compulsive disorder and bipolar disorder in children and adolescents. Bipolar Disord. 12, 185-195.

Kemp, D.E., Sylvia, L.G., Calabrese, J.R., Nierenberg, A.A., Thase, M.E., Reilly-Harrington, N.A., Ostacher, M.J., Leon, A.C., Ketter, T.A., Friedman, E.S., Bowden, C.L., Rabideau, D.J., Pencina, M., Iosifescu, D.V., 2014. General medical burden in bipolar disorder: findings from the LiTMUS comparative effectiveness trial. Acta Psychiatr. Scand. 129, 24-34.

Kim, S.W., Berk, L., Kulkarni, J., Dodd, S., de Castella, A., Fitzgerald, P.B., Amminger, G.P., Berk, M., 2014. Impact of comorbid anxiety disorders and obsessivecompulsive disorder on 24-month clinical outcomes of bipolar I disorder. J. Affect. Disord. 166, 243-248.

Koyuncu, A., Tukel, R., Ozyildirim, I., Meteris, H., Yazici, O., 2010. Impact of obsessive-compulsive disorder comorbidity on the sociodemographic and clinical features of patients with bipolar disorder. Compr. Psychiatry 51, 293-297.

Kruger, S., Braunig, P., Cooke, R.G., 2000. Comorbidity of obsessive-compulsive disorder in recovered inpatients with bipolar disorder. Bipolar Disord. 2, 71-74.

Krüger, S., Cooke, R.G., Hasey, G.M., Jorna, T., 1995. Comorbidity of obsessive compulsive disorder in bipolar disorder. J. Affect. Disord. 34, 117-120.

Liberati, A., Altman, D.G., Tetzlaff, J., Mulrow, C., Gotzsche, P.C., Ioannidis, J.P., Clarke, M., Devereaux, P.J., Kleijnen, J., Moher, D., 2009. The PRISMA statement for reporting systematic reviews and meta-analyses of studies that evaluate healthcare interventions: explanation and elaboration. Br. Med. J. 339, b2700.

Magalhaes, P.V., Kapczinski, N.S., Kapczinski, F., 2010. Correlates and impact of obsessive-compulsive comorbidity in bipolar disorder. Compr. Psychiatry 51, 353-356.

Maina, G., Albert, U., Pessina, E., Bogetto, F., 2007. Bipolar obsessive-compulsive disorder and personality disorders. Bipolar Disord. 9, 722-729.

Marazziti, D., Dell'osso, L., di Nasso, E., Pfanner, C., Presta, S., Mungai, F., Cassano, G. B., 2002. Insight in obsessive-compulsive disorder: a study of an Italian sample. Eur. Psychiatry 17, 407-410.

Masi, G., Millepiedi, S., Mucci, M., Bertini, N., Milantoni, L., Arcangeli, F., 2005. A naturalistic study of referred children and adolescents with obsessive-compulsive disorder. J. Am. Acad. Child Adolesc. Psychiatry 44, 673-681.

Masi, G., Millepiedi, S., Perugi, G., Pfanner, C., Berloffa, S., Pari, C., Mucci, M., Akiskal, H.S., 2010. A naturalistic exploratory study of the impact of demographic, phenotypic and comorbid features in pediatric obsessive-compulsive disorder. Psychopathology 43, 69-78.

Mayer-Gross, W., Slater, E., Roth, M., 1969. Clinical Psychiatry. Elsevier Health Sciences, London.

Mcelroy, S.L., Altshuler, L.L., Suppes, T., Keck Jr., P.E., Frye, M.A., Denicoff, K.D., Nolen, W.A., Kupka, R.W., Leverich, G.S., Rochussen, J.R., Rush, A.J., Post, R.M., 2001 Axis I psychiatric comorbidity and its relationship to historical illness variables in 288 patients with bipolar disorder. Am. J. Psychiatry 158, 420-426.

Merikangas, K.R., Akiskal, H.S., Angst, J., Greenberg, P.E., Hirschfeld, R.M., Petukhova, M., Kessler, R.C., 2007. Lifetime and 12-month prevalence of bipolar spectrum disorder in the National Comorbidity Survey replication. Arch. Gen. Psychiatry 64, 543-552.

Morel, B.A., 1860. Traité des Maladies Mentales. Masson, Paris. 
Mukaddes, N.M., Fateh, R., 2010. High rates of psychiatric co-morbidity in individuals with Asperger's disorder. World J. Biol. Psychiatry 11, 486-492.

Perugi, G., Akiskal, H.S., Gemignani, A., Pfanner, C., Presta, S., Milanfranchi, A., Lensi, P., Ravagli, S., Maremmani, I., Cassano, G.B., 1998. Episodic course in obsessivecompulsive disorder. Eur. Arch. Psychiatry Clin. Neurosci. 248, 240-244.

Perugi, G., Akiskal, H.S., Pfanner, C., Presta, S., Gemignani, A., Milanfranchi, A., Lensi, P., Ravagli, S., Cassano, G.B., 1997. The clinical impact of bipolar and unipolar affective comorbidity on obsessive-compulsive disorder. J. Affect. Disord. 46, $15-23$.

Perugi, G., Akiskal, H.S., Ramacciotti, S., Nassini, S., Toni, C., Milanfranchi, A., Musetti, L., 1999. Depressive comorbidity of panic, social phobic, and obsessivecompulsive disorders re-examined: is there a bipolar II connection? J. Psychiatr. Res. 33, 53-61.

Perugi, G., Toni, C., Frare, F., Travierso, M.C., Hantouche, E., Akiskal, H.S., 2002. Obsessive-compulsive-bipolar comorbidity: a systematic exploration of clinical features and treatment outcome. J. Clin. Psychiatry 63, 1129-1134.

Reddy, Y.C., Reddy, P.S., Srinath, S., Khanna, S., Sheshadri, S.P., Girimaji, S.C., 2000 Comorbidity in juvenile obsessive-compulsive disorder: a report from India. Can. J. Psychiatry 45, 274-278.

Saunders, E.F. Fitzgerald, K.D., Zhang. P. Mcinnis, M.G., 2012. Clinical features of bipolar disorder comorbid with anxiety disorders differ between men and women. Depress. Anxiety 29, 739-746.

Shashidhara, M., Sushma, B.R., Viswanath, B., Math, S.B., Janardhan Reddy, Y.C. 2015. Comorbid obsessive compulsive disorder in patients with bipolar-I disorder. J. Affect. Disord. 174, 367-371.

Shon, S.H., Joo, Y., Park, J., Youngstrom, E.A., Kim, H.W., 2014. Comparison of clinica characteristics of bipolar and depressive disorders in Korean clinical sample of youth: a retrospective chart review. Eur. Child Adolesc. Psychiatry 23, 307-316.

Simon, N.M., Otto, M.W., Wisniewski, S.R., Fossey, M., Sagduyu, K., Frank, E., Sachs, G.S., Nierenberg, A.A., Thase, M.E., Pollack, M.H., 2004. Anxiety disorder comorbidity in bipolar disorder patients: data from the first 500 participants in the Systematic Treatment Enhancement Program for Bipolar Disorder (STEPBD). Am. J. Psychiatry 161, 2222-2229.
Simon, N.M., Smoller, J.W., Fava, M., Sachs, G., Racette, S.R., Perlis, R., Sonawalla, S., Rosenbaum, J.F., 2003. Comparing anxiety disorders and anxiety-related traits in bipolar disorder and unipolar depression. J. Psychiatr. Res. 37, 187-192.

Strakowski, S.M., Sax, K.W., Mcelroy, S.L., Keck Jr., P.E., Hawkins, J.M., West, S.A., 1998. Course of psychiatric and substance abuse syndromes co-occurring with bipolar disorder after a first psychiatric hospitalization. J. Clin. Psychiatry 59, 465-471.

Strakowski, S.M., Tohen, M., Stoll, A.L., Faedda, G.L., Goodwin, D.C., 1992. Comorbidity in mania at first hospitalization. Am. J. Psychiatry 149, 554-556.

Stroup, D.F., Berlin, J.A., Morton, S.C., Olkin, I., Williamson, G.D., Rennie, D., Moher, D., Becker, B.J., Sipe, T.A., Thacker, S.B., 2000. Meta-analysis of observational studies in epidemiology: a proposal for reporting. Meta-analysis Of Observational Studies in Epidemiology (MOOSE) group. J. Am. Med. Assoc. 283, 2008-2012.

Tillman, R., Geller, B., Bolhofner, K., Craney, J.L., Williams, M., Zimerman, B., 2003. Ages of onset and rates of syndromal and subsyndromal comorbid DSM-IV diagnoses in a prepubertal and early adolescent bipolar disorder phenotype. J. Am. Acad. Child Adolesc. Psychiatry 42, 1486-1493.

Timpano, K.R., Rubenstein, L.M., Murphy, D.L., 2012. Phenomenological features and clinical impact of affective disorders in OCD: a focus on the bipolar disorder and OCD connection. Depress. Anxiety 29, 226-233.

Tonna, M., Amerio, A., Ottoni, R., Paglia, F., Odone, A., Ossola, P., de Panfilis, C., Ghaemi, S.N., Marchesi, C. 2015. The clinical meaning of obsessive-compulsive symptoms in bipolar disorder and schizophrenia. Aust. N. Z. J. Psychiatry.

Tukel, R., Oflaz, S.B., Ozyildirim, I., Aslantas, B., Ertekin, E., Sozen, A., Alyanak, F., Atli, H., 2007. Comparison of clinical characteristics in episodic and chronic obsessive-compulsive disorder. Depress Anxiety 24, 251-255.

Vazquez, G.H., Baldessarini, R.J., Tondo, L., 2014. Co-occurrence of anxiety and bipolar disorders: clinical and therapeutic overview. Depress Anxiety 31, 196-206.

Zutshi, A., Reddy, Y.C., Thennarasu, K., Chandrashekhar, C.R., 2006. Comorbidity of anxiety disorders in patients with remitted bipolar disorder. Eur. Arch. Psychiatry Clin. Neurosci. 256, 428-436. 